\title{
An Analysis of Individual and Contextual-Level Disparities in Screening, Treatment, and Outcomes for Hepatocellular Carcinoma
}

\author{
Joshua P Kronenfeld \\ Neha Goel (D) \\ Division of Surgical Oncology, \\ Department of Surgery, University of \\ Miami Miller School of Medicine, Miami, \\ FL, USA
}

\begin{abstract}
Hepatocellular carcinoma (HCC) is the most common primary malignancy of the liver and affects patients of all genders, races, ethnicities, and socioeconomic status. While the causes of HCC are numerous, the primary etiology is cirrhosis from alcohol and nonalcoholic fatty liver disease in the United States and from infectious agents such as Hepatitis $\mathrm{B}$ and Hepatitis $\mathrm{C}$ in the developing world. In patients at-risk for developing HCC, screening is recommended with ultrasound imaging and alpha fetoprotein laboratory tests. In socioeconomically vulnerable patients, however, individual-level barriers (eg, insurance status) and contextual-level disparities (eg, health facilities) may not be readily available, thus limiting screening. Additional challenges faced by racial/ethnic minorities can further challenge the spectrum of HCC care and lead to inadequate screening, delayed diagnosis, and unequal access to treatment. Efforts to improve these multilevel factors that lead to screening and treatment disparities are critical to overcoming challenges. Providing health insurance to those without access, improving societal challenges that confine patients to a lower socioeconomic status, and reducing challenges to seeking healthcare can decrease the morbidity and mortality of these patients. Additionally, engaging with communities and allowing them to collaborate in their own healthcare can also help to attenuate these inequities. Through collaborative multidisciplinary change, we can make progress in tackling disparities in vulnerable populations to achieve health equity
\end{abstract}

Keywords: hepatocellular carcinoma, healthcare disparities, social determinants of health

\section{Background}

Hepatocellular carcinoma (HCC) is the most common primary malignancy of the liver and affects people of all genders, races, ethnicities, and socioeconomic status. ${ }^{1}$ Worldwide, the incidence varies from region to region, with the highest incidence in Asia and Africa where more than 20 people per 100,000 are diagnosed with HCC. ${ }^{1}$ In the United States, the incidence is lower at about 5 per $100,000 .^{2}$ Worldwide, males are nearly twice as likely to develop HCC as females, and the median age of diagnosis is 62. . $^{3,4}$

Patients with underlying liver disease are at particularly high-risk for developing HCC. ${ }^{2}$ In the United States, the predominant cause of HCC is cirrhosis mainly from alcohol and non-alcoholic fatty-liver disease. ${ }^{5}$ In the developing world, however, infectious etiologies such as Hepatitis B and $\mathrm{C}$ are the principal causal agents. ${ }^{6}$ A patient's underlying genetic factors may also predispose the individual to develop HCC including alpha-1 antitrypsin deficiency. ${ }^{7}$ Additionally, having multiple risk
Correspondence: Neha Goel Department of Surgery, University of Miami Miller School of Medicine, Sylveste Comprehensive Cancer Center, II 20

NW 14th Street, Suite 4I0, Miami, Fl, 33136, USA

Tel + I $630806-1440$

$\mathrm{Fax}+\mathrm{I} 305243-4907$

Email neha.goel@med.Miami.edu 
factors may have a synergistic effect on the risk of HCC development. For example, patients with Hepatitis $\mathrm{C}$ and heavy alcohol intake have a 2.3 times greater odds of developing $\mathrm{HCC}$ than patients with Hepatitis $\mathrm{C}$ alone. ${ }^{8}$

The incidence of HCC increased throughout the world in the 1980s and 1990s as the incidence of Hepatitis C virus, diabetes, obesity, and metabolic syndrome has increased. ${ }^{1}$ On the other hand, over the past decade, increased screening for at-risk patients, changes to the epidemiology of underlying liver disease (eg treatment for Hepatitis B and Hepatitis C), broadened surgical indications, and improved availability of systemic therapy, have led to a decrease in HCC incidence, prevalence, and mortality throughout the western world. ${ }^{9,10}$ However, despite these medical advancements, disparities in outcomes remain among vulnerable populations (eg, racial/ethnic minorities, low-income populations, uninsured) due to unequal distribution, access, and receipt of medical care. ${ }^{11}$ As a result, significant disparities across the HCC continuum, from screening to treatment to outcomes, exist. Investigation into the causes of these disparities is warranted in an effort to ameliorate inequities and improve survival for all patients with HCC. The objective of this paper is to provide a contemporary review of individuallevel (eg, race/ethnicity and insurance) and contextual-level [social determinants of health (SDoH)] measures that impact disparities in HCC screening, treatment, and survival outcomes.

\section{Contextual-Level Measures}

Social determinants of Health $(\mathrm{SDoH})$ are contextualfactors, apart from medical care that influence healthcare outcomes (Figure 1). They encompass five general domains that categorize the challenges faced by vulnerable populations. ${ }^{12,13}$ These domains include: neighborhood and built environment, social and community context, health and healthcare, economic stability, and education. ${ }^{12}$

\section{Neighborhood and Built Environment \& Social and Community Context}

Neighborhood-level income can influence the diagnostic rates (upstream effects) and outcomes (downstream effects) of patients with HCC. ${ }^{14}$ In fact, patients with the highest socioeconomic status, as defined by neighborhood-level income, were found to have a $10 \%$ increased survival advantage when compared to patients at the lowest income level. ${ }^{15}$ While some of these outcomes may be attributed to accessto-care and health insurance disparities, discussed later, additional factors must be explored to fully understand why these disparate outcomes by income are seen. ${ }^{16}$

Patients from low-income neighborhoods have a higher incidence of HCC than the general population. ${ }^{17}$ Increased risk factors may help to explain this phenomenon, and one explanation is that individuals living in these low-income neighborhoods may have challenges in affording nutritious and health food options or may experience food

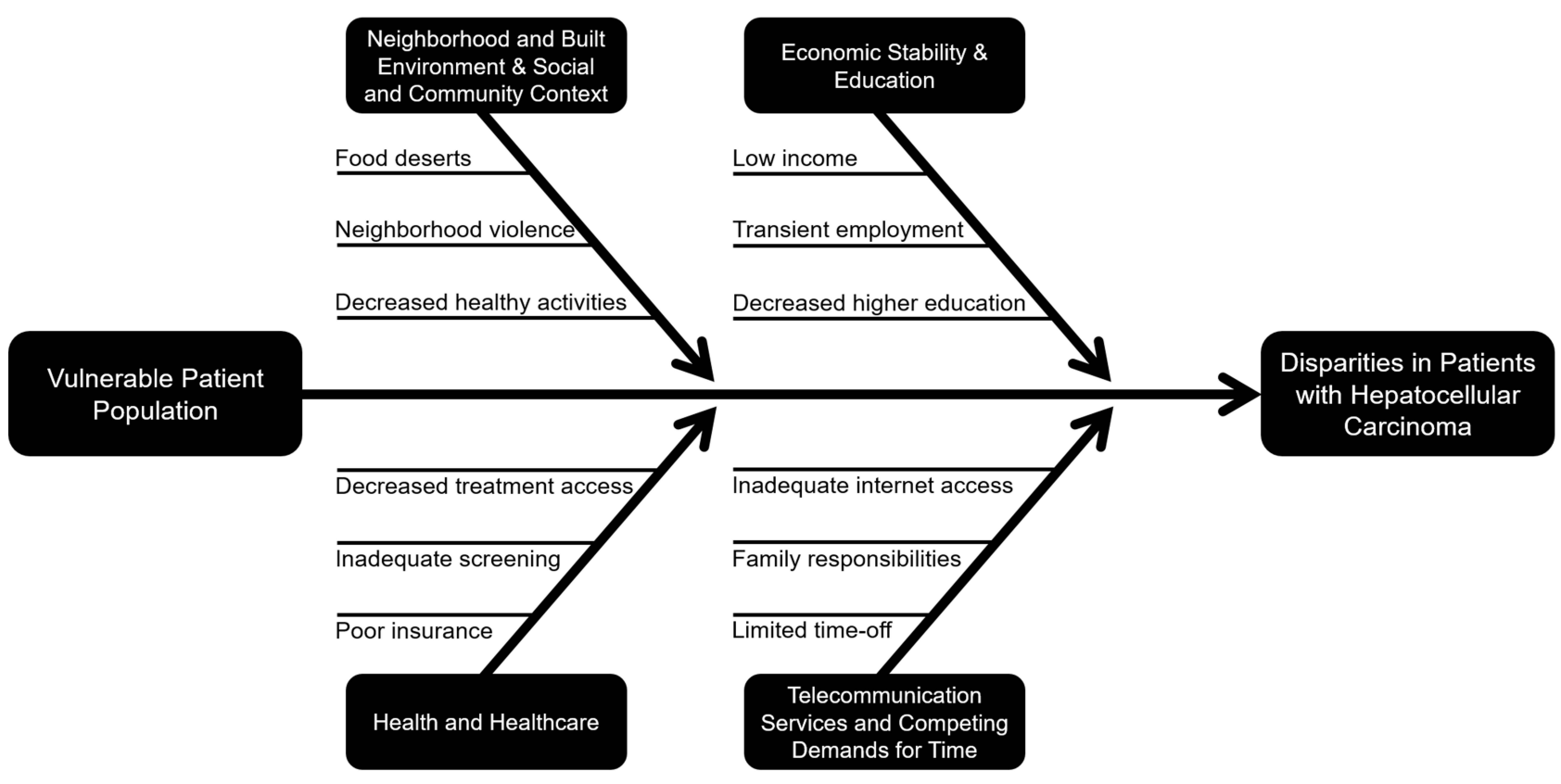

Figure I Contextual-Level Measures of HCC Disparities in Screening, Treatment, and Outcomes. 
insecurity. ${ }^{18,19}$ These patients turn towards high-fat and carbohydrate rich foods from fast-food chains due to their lower cost. ${ }^{20,21}$ In addition to cost constraints, availability of fresh produce may be limited to patients of lower socioeconomic status due to food deserts in many of their communities. ${ }^{22}$ Studies have demonstrated that individuals in lower socioeconomic neighborhoods tend to live further from supermarkets than those in more affluent areas. ${ }^{23}$ This high-fat, nutritionally poor diet may predispose patients to develop nonalcoholic fatty liver disease, a common cause of cirrhosis that can lead to the development of $\mathrm{HCC}^{24,25}$

Individuals from low-income neighborhoods also tend to have an increased prevalence of diabetes and obesity, coupled with decreased exercise due to lack of green space and parks, increases risk for non-alcoholic fatty liver disease associated-HCC that has been demonstrated in both human and mouse models. ${ }^{26-30}$ Additionally, low-income neighborhoods tend to have increased neighborhood violence, and individuals may be resistant to partake in outdoor activities. ${ }^{31,32}$ The cumulative effects of decreased exercise and increased diabetes can expedite HCC transformation in at-risk individuals and increase HCC tumor growth in patients who have already developed disease. ${ }^{27,33}$ While these factors may yield an increased incidence of HCC among individuals from low-income neighborhoods once a patient has a malignancy, early diagnosis and comprehensive treatment is necessary to improving outcomes.

\section{Health and Healthcare}

Access to health insurance can drastically alter the outcomes for patients with HCC. ${ }^{34-39}$ In patients with potentially curative (non-metastatic) disease, privately insured individuals have a median overall survival of 34 months, while patients without health insurance can have a median overall survival as low as 9 months. ${ }^{40}$ Lack of health insurance has also been shown to be an independent predictor of decreased overall survival when controlling for other potential sociodemographic confounders. ${ }^{14,40}$ The exact etiology of this decreased survival in uninsured and underinsured patients is unknown, but numerous challenges faced by these patients may offer some understanding of the origins of this disparity. ${ }^{41}$

Patients without adequate health insurance coverage are less likely to be screened for HCC. ${ }^{42,43}$ These patients often lack a usual source of healthcare or primary care physician. ${ }^{44}$ In patients who have annual well-care physicals, as recommended by the Centers for Disease Control and Prevention, physicians may discover potential risk-factors or early signs of cirrhosis based on history, physical exam, or laboratory findings. ${ }^{45,46}$ In these patients with concerning features, additional laboratory and imaging tests can be ordered to uncover occult malignancies (eg HCC) ${ }^{47}$ In high-risk patients where a malignancy is not discovered, a screening protocol can be implemented to identify $\mathrm{HCC}$ in its early stages. ${ }^{48}$ These services may be inaccessible to patients without health insurance.

Screening is recommended for all patients with cirrhosis of the liver, regardless of etiology. ${ }^{47}$ Patients are screened with ultrasound and serum alpha fetoprotein levels to uncover malignancies in the liver parenchyma. ${ }^{49}$ Additionally, the 2018 guidelines by the American Association for the Study of Liver Disease recommend screening for patients at high risk for Hepatitis $\mathrm{C}$ including current or former intravenous drug users, patients who received solid organ transplantations, patients who received a blood transfusion before 1992, or those born between 1945 and $1965 .{ }^{48,50,51}$ Those with diagnosed Hepatitis $\mathrm{C}$ require close follow-up, and are screened with an abdominal ultrasound and alpha fetoprotein levels every six months if cirrhosis develops. ${ }^{50,52}$ Patients without insurance often are not able to obtain these screening services due to lack of access to a primary care physician to order screening exams. ${ }^{41}$

Early diagnosis of HCC, and most other malignancies, is imperative to improve clinical outcomes. ${ }^{53}$ If identified early, HCC may be treated with local ablations or smaller curative operative interventions. ${ }^{54}$ If diagnosed at later stages, however, multimodal treatment consisting of systemic therapy, liver-directed-therapy, extensive surgical resection, or even liver transplantation may be required. ${ }^{55}$ Not surprisingly, studies have demonstrated that patients without insurance are more likely to be diagnosed with later-stage or metastatic disease than patients with adequate coverage. ${ }^{43}$ This drastically affects survival outcomes and drives the disparity seen between insurance types. ${ }^{40}$

Even if uninsured or underinsured patients are diagnosed with curative HCC, navigating the healthcare system remains a challenge. Studies have shown that access to cancer care coordinators or patient navigators can improve clinical outcomes. ${ }^{56}$ These navigators are able to more easily schedule appointments with specialists, arrange for necessary imaging or procedures, and increase screening by up to $50 \% .{ }^{57,58}$ Uninsured patients are often 
without these patient navigators and have a more difficult experience in schedule these appointments. ${ }^{58}$ This may cause patients to wait weeks to months to visit with all necessary specialists and can significantly delay care and lead to disease progression. ${ }^{59}$

Frequent medical appointments with medical oncologists, surgical oncologists, radiation oncologists, and other medical specialties may also be challenging and costly due to transportation costs, time off work, and copayments for patients without insurance. ${ }^{60}$ Additionally, many facilities do not offer systemic therapy, liver-directed therapies, or surgery for patients unable to cover the cost. ${ }^{61}$ Moreover, patients without health insurance face additional challenges in the postoperative period or while on systemic therapy such as frequent treatment visits and eventually surveillance visits. ${ }^{60}$ While the first few visits are often covered with the cost of the surgery, subsequent follow-up visits require out-of-pocket expenses. ${ }^{62}$ Patients without health insurance therefore do not maintain consistent follow-up and should complications or symptoms of recurrence arise, they are not discovered until they have caused significant morbidity, leading to greater financial toxicity. ${ }^{11,63}$ Additionally, in the postoperative period, access to nutritional support services, physical therapy, home health, and other ancillary support mechanisms may be out of monetary reach for patients without insurance. ${ }^{64}$ These support mechanisms, while not always necessary, have been shown to improve outcomes in HCC. ${ }^{65}$ The cumulative financial burden of the aforementioned challenges may be an underlying cause of disparities in survival outcomes between HCC patients with and without health insurance. ${ }^{40}$

\section{Economic Stability and Education}

Inconsistent or inadequate employment may also lead to HCC disparities. Studies reveal that individuals of lower socioeconomic status are likely to have children that are also of lower socioeconomic status, perpetuating the cycle of poverty in families. ${ }^{66}$ An underlying cause of employment disparities begins with disparate education systems in low-income neighborhoods in which these individuals (and future generations) reside. ${ }^{67}$ Patients of lower socioeconomic status are also less likely to attain a high-school diploma, receive a bachelor's degree, or have a graduate or advanced professional degree, further limiting employment opportunities. ${ }^{68}$

These inequalities in education among individuals from low-income neighborhoods leads to challenges in securing stable employment. ${ }^{69}$ These individuals are less likely to have jobs or careers that provide health insurance and can lead to the many disparities discussed above. ${ }^{69}$ Additionally, the education barriers faced by individuals of lower socioeconomic status lead to lower wages and a decreased ability to pay for HCC treatment. ${ }^{70}$ Finally, decreased education may lead to disparities in healthcare literacy, and patients may have challenges in participating in their own care and informed healthcare decision making, further exacerbating disparities in HCC survival outcomes. $^{71}$

\section{Individual-Level Measures Race and Ethnicity}

In addition to the aforementioned contextual-level disparities, racial and ethnic minorities face additional challenges when seeking HCC care. ${ }^{72}$ In particular, Black and Hispanic HCC patients must overcome barriers throughout their workup, diagnosis, and treatment of HCC. ${ }^{73,74}$ Both populations are more likely to be diagnosed with HCC in the emergency department than an outpatient facility, likely indicating a reduced screening of these patients. ${ }^{11}$ As previously discussed, patients not afforded primary care and screening services are also more likely to present with later-stage disease that may not be amenable to curative-intent treatment. ${ }^{17}$ Additionally, Black patients are less likely to receive a liver transplant, and studies have demonstrated that even in Black patients who receive treatment with a liver transplantation, survival is still less than patients of other races. ${ }^{75-77}$

\section{Language}

Language barriers also play a role in the disparities experienced by racial and ethnic minorities. ${ }^{78}$ For example, many Hispanic patients may not be fluent in English. ${ }^{79}$ Other patients of different racial and ethnic backgrounds may also have limited fluency in English. This provides barriers to these patients in a variety of ways. Jobs that provide health insurance may be less attainable to individuals without English literacy. ${ }^{80}$ Minority patients that are not fluent in English may also face employment discrimination limiting access to careers that include adequate income, health insurance, and other important benefits. ${ }^{81}$

Additionally, racial/ethnic minorities may be undocumented in the United States. ${ }^{82}$ This further complicates the possibility of receiving health insurance, and many patients may be limited to hospital-based plans or 
Medicaid insurance for those who qualify. ${ }^{83}$ Furthermore, a scarcity of resources for individuals and their families who have recently migrated to the United States can lead to challenges in learning English and securing health insurance benefits. ${ }^{84-86}$

\section{Competing Demands for Time and Telecommunication Services}

Additional individual-level measures of disparity may include competing demands for time. Patients with steady employment and insurance may have more job flexibility allowing for time off. ${ }^{87}$ On the other hand, patients without job security may fear that if time is requested off, they may be in jeopardy of losing their jobs. ${ }^{88}$ Additional individual-level measures that may affect HCC patients are childcare or other caregiver responsibilities that may make it challenging for patients to attend appointments. ${ }^{89,90}$ This can lead to delays in diagnosis, which has profound survival implications. ${ }^{45}$

A more contemporary individual-level factor causing disparities in HCC patients are inequality in telecommunication services among patients. The COVID-19 pandemic has elucidated the possibility of seeing a physician remotely for clinical evaluations and follow-up visits. ${ }^{91}$ While telemedicine can help reach patients who cannot visit a clinic, such as those in rural or those with competing demands for time, the patient must have the appropriate technology to facilitate a telehealth visit. ${ }^{92}$ Although seemingly ubiquitous, high-speed internet services may also not be accessible to all patients. ${ }^{93}$ Additionally, some patients of lower socioeconomic status utilize local libraries or public hotspots for their Internet connectivity, a barrier not conducive to engaging in a telehealth visit. $^{94,95}$

\section{Strategies to Overcome Individual and Contextual-Level Barriers to Care \\ Access to Insurance}

Insurance appears to be the most important factor affecting the diagnosis (upstream effects), treatment, and survival (downstream effects) of patients with HCC. ${ }^{11,40,96}$ As previously mentioned, median overall survival differs dramatically between patients with private health insurance (greater than 30 months) and those without any health insurance (less than 10 months). ${ }^{40}$ Efforts must be made to increase health insurance accessibility and enrollment for all HCC patients to improve screening and treatment delivery. ${ }^{43}$ The Affordable Care Act has sought to expand access to all, and while many improvements have been made, much work is still needed in this arena. ${ }^{97}$

Medicaid expansion is one way to continue to improve access. ${ }^{98}$ Studies have revealed that access to Medicaid or any type of insurance can improve HCC screening. ${ }^{11,43}$ This suggests that having insurance, particularly plans that cover liver-directed therapies or surgical interventions, independently provide survival benefits to patients. $^{40,99,100}$ In other malignancies, studies have shown that expansion of public health-insurance options has resulted in a lower percentage of late-stage diagnoses and ultimately improved survival. ${ }^{101}$

Enhanced primary care physician visits and screening services for insured patients may also lead to improved patient outcomes due to earlier diagnoses. ${ }^{43}$ Additionally, patient navigators are often accessible to insured patients, which can help them to navigate the healthcare system and schedule appropriate appointments. ${ }^{57}$ Finally, access to systemic therapy, liver-directed-therapies and surgical interventions are more accessible to patients with insurance. ${ }^{61}$ Given the importance of insurance across the HCC continuum, access to insurance remains a critical step in decreasing HCC disparities in vulnerable populations.

\section{Improved Education Systems}

While healthcare reform through access to care for all would be the "golden ticket" to health equity, addressing the root causes of healthcare disparities is also critical. As previously discussed, education can have profound impacts on future careers and access to insurance, along with other socioeconomic benefits. ${ }^{67,102}$ Investments must be made to improve school systems nationwide, ensuring all students have an equal opportunity for success. ${ }^{103}$ An additional strategy to improve the education of individuals might be through the implementation of School Choice programs where parents can send their students to a school system with higher quality education. ${ }^{104,105}$ With better education, improved employment can be secured, and health insurance can be attained. ${ }^{106}$

While the effects of poor school systems on future healthcare have previously been discussed, the effect of lost learning from the COVID-19 pandemic are not yet understood. ${ }^{107}$ Students in many areas throughout the country and world were out of the classroom for many months to a year due to safety concerns from the COVID- 
19 pandemic. ${ }^{107,108}$ Numerous studies predict lasting future effects on knowledge and performance on standardized examinations. ${ }^{107}$ These effects are predicted to affect individuals of poor socioeconomic status more than affluent students. ${ }^{109}$ This disparity may be due to more affluent children having tutors to fill learning gaps or parents that can remain home to work with them on their work. ${ }^{109}$ Additional vigilance is necessary to make up for this lost knowledge, especially in low-income neighborhoods with individuals of poor socioeconomic status. ${ }^{110}$ Without careful attention, it is possible that future disparities in HCC and other cancer care will be exacerbated due to lasting effects of the COVID-19 pandemic.

\section{Access to Healthcare}

In addition to increased insurance access, efforts should be made to improve the ease in which a patient can access the healthcare system. Telehealth is growing in popularity throughout the world and has been particularly helpful throughout the COVID-19 pandemic. $^{91}$ Although imaging and procedures cannot take place remotely, initial consultations, follow-up visits, and postoperative visits may be conducted through a virtual platform. ${ }^{111}$ This expansion to telehealth services has improved the reach of providers, allowing for them to care for patients who may otherwise have difficulty accessing the medical system. ${ }^{112}$ Additionally, patients who have competing demands for time, as discussed above, can consult with a physician without needing to leave their homes. ${ }^{91}$ There are, however, significant disparities that have been elucidated as telehealth has grown in popularity. ${ }^{112}$

As previously discussed, vulnerable patients may not have access to computers or high-speed internet services needed to facilitate a telehealth visit. ${ }^{113}$ Strategies must be implemented to bridge the technology gap among populations of different socioeconomic status. One strategy has been to provide broadband internet coverage to vulnerable communities. ${ }^{114}$ Additional initiatives have hoped to provide internet-ready devices that will allow for these telehealth visits. ${ }^{115}$ While technology can certainly ease the burden of frequent clinic visits, patients without access to these devices are subjected to continued disparities. ${ }^{112}$

In addition to telehealth and infrastructure challenges faced by many patients, others face challenges in securing transportation to their clinical appointments. In urban settings, many patients may not have vehicles and rely on public transportation to get to and from their medical appointments. ${ }^{116}$ After medical and surgical treatments for HCC, many patients have significant physical challenges that make public busses and trains a challenging means of transportation. ${ }^{117}$ In fact, many patients are unable to follow-up due to inadequate transportation, and these missed appointments can negatively impact the trajectory of their HCC care. ${ }^{116}$ Programs to provide transportation can drastically improve attendance to clinic appointments and other scheduled visits. ${ }^{118}$ Some hospitalsystems are providing these services to assist patients, but additional resources are available through Medicare and other insurance plans. ${ }^{119}$ Specifically, the Veterans Affairs healthcare system has a robust infrastructure to assist with transportation. ${ }^{120}$ Of course, patients without insurance may not be afforded these opportunities, so local, regional, and national efforts should be made to improve transportation services to and from required medical visits. ${ }^{116}$

\section{Culturally Competent Care and Community Engagement}

As previously discussed, racial and ethnic minority patients are subjected to significant healthcare disparities. ${ }^{72}$ These disparities are exacerbated by disparate oncology care for malignancies such as HCC. ${ }^{121}$ Ensuring adequate access and equitable care for minority patients begins with understanding a patient's cultural beliefs and practices. ${ }^{122}$ For example, some cultures may have different approaches to cancer care with some patients choosing to keep their malignancy hidden from their families. ${ }^{123}$ Other cultures may choose to involve many family members in healthcare decisions and treatment course. ${ }^{123}$ Understanding these differences may help providers better care for patients and may help patients become more comfortable with their physicians. ${ }^{124}$ One strategy to enhance patient comfort is to increase the hiring of diverse healthcare workers. ${ }^{125}$ Racial and ethnic minorities are underrepresented in healthcare fields, but improved diversity may assist with patient comfort and trust as they can be cared for by a provider that understands their unique cultural considerations. ${ }^{126-128}$

Translator and language services are also imperative to decreasing disparities in care for HCC and other malignancies. ${ }^{129}$ While many patients are partially fluent in English, it is important to engage with an official interpreter or translator service when discussing important medical decisions, especially care for their HCC malignancy. ${ }^{129,130}$ Although providers may partially be fluent in a patient's native language, stylistics nuances 
and different dialects that vary across country of origin can complicate patient and provider understanding. ${ }^{131}$

In addition to culturally competent care, disparities can be alleviated with enhanced community engagement for racial and ethnic minorities. ${ }^{124}$ Patients in underserved communities appreciate engaging with healthcare providers so their healthcare needs can be understood. ${ }^{132}$ In some communities, patients may be interested in screening programs for malignancies, while other communities may have other concerns such as smoking cessation or sexually transmitted infections. ${ }^{132,133}$ Providers and healthcare systems must engage with community leaders to understand the needs of a particular community. ${ }^{134}$ While these important considerations do not directly impact $\mathrm{HCC}$ care, gaining the trust of a community is a necessary first step to providing care. Finally, Federally Qualified Health Centers (FQHCs) offer patients a medical home where primary care and specialty services can be accessed within a community and may further assist in ensuring patient trust and improving health outcomes. ${ }^{135,136}$ Without trust between providers and individuals, patients may be wary of seeking screening services, consulting with a physician after diagnosis, or undergoing liver-directed therapies and surgical procedures for HCC. ${ }^{137}$

\section{Conclusions}

$\mathrm{HCC}$ is a complex malignancy that requires comprehensive screening of at-risk patients and multimodality treatment regimens including systemic therapy, liver-directed therapy, and surgery. Individual and contextual-level measures can drastically impact the services accessible and treatments provided to patients with HCC. Providers and healthcare systems must continue to work towards providing equitable care to all patients in an effort to reduce disparities and improve healthcare outcomes in vulnerable populations.

\section{Acknowledgments}

This research was supported by the National Institute of Health under a training grant, T32CA211034, and a K-award, K12CA226330.

\section{Funding}

Joshua P. Kronenfeld: NIH T32CA211034; Neha Goel: NIH K12CA226330.

\section{Disclosure}

The authors report no conflicts of interest in this work.

\section{References}

1. McGlynn KA, London WT. The global epidemiology of hepatocellular carcinoma: present and future. Clin Liver Dis. 2011;15 (2):223-x. doi:10.1016/j.cld.2011.03.006

2. Mittal S, El-Serag HB. Epidemiology of hepatocellular carcinoma: consider the population. J Clin Gastroenterol. 2013;47 Suppl:S2-6.

3. Hefaiedh R, Ennaifer R, Romdhane H, et al. Gender difference in patients with hepatocellular carcinoma. Tunis Med. 2013;91(89):505-508.

4. Yang JD, Altekruse SF, Nguyen MH, Gores GJ, Roberts LR. Impact of country of birth on age at the time of diagnosis of hepatocellular carcinoma in the United States. Cancer. 2017;123 (1):81-89.

5. Pocha C, Xie C. Hepatocellular carcinoma in alcoholic and non-alcoholic fatty liver disease-one of a kind or two different enemies? Transl Gastroenterol Hepatol. 2019;4:72.

6. Kew MC. Hepatocellular carcinoma in developing countries: prevention, diagnosis and treatment. World J Hepatol. 2012;4 (3):99-104.

7. Antoury C, Lopez R, Zein N, Stoller JK, Alkhouri N. Alpha-1 antitrypsin deficiency and the risk of hepatocellular carcinoma in end-stage liver disease. World J Hepatol. 2015;7(10):1427-1432.

8. Hutchinson SJ, Bird SM, Goldberg DJ. Influence of alcohol on the progression of hepatitis $\mathrm{C}$ virus infection: a meta-analysis. Clin Gastroenterol Hepatol. 2005;3(11):1150-1159.

9. Rich NE, Yopp AC, Singal AG, Murphy CC. Hepatocellular Carcinoma Incidence Is Decreasing Among Younger Adults in the United States. Clin Gastroenterol Hepatol. 2020;18(1):242248 e245.

10. Wong RJ, Kim D, Ahmed A, Singal AK. Patients with hepatocellular carcinoma from more rural and lower-income households have more advanced tumor stage at diagnosis and significantly higher mortality. Cancer. 2021;127(1):45-55. doi:10.1002/ cncr.33211

11. Kronenfeld JP, Ryon EL, Goldberg D, et al. Disparities in Presentation at Time of Hepatocellular Carcinoma Diagnosis: a United States Safety-Net Collaborative Study. Ann Surg Oncol. 2021;28(4):1929-1936. doi:10.1245/s10434-020-09156-4

12. People H. Social Determinants of Health. US Department of health and human services; 2020. Available from: https://www. healthypeople.gov/2020/topics-objectives/topic/socialdeterminants-health/interventions-resources-: : text=Healthy\% 20People\%202020\%20organizes\%20the,5)\%20Social\%20and\% 20Community\%20Context.Published2021. Accessed September 3, 2021.

13. Braveman P, Gottlieb L. The social determinants of health: it's time to consider the causes of the causes. Public Health Rep. 2014;129(Supp1 2):19-31.

14. Sellers CM, Uhlig J, Ludwig JM, et al. The impact of socioeconomic status on outcomes in hepatocellular carcinoma: inferences from primary insurance. Cancer Med. 2019;8 (13):5948-5958.

15. Jembere N, Campitelli MA, Sherman M, et al. Influence of socioeconomic status on survival of hepatocellular carcinoma in the Ontario population; a population-based study, 1990-2009. PLoS One. 2012;7(7):e40917.

16. Yun EH, Lim MK, Oh JK, et al. Combined effect of socioeconomic status, viral hepatitis, and lifestyles on hepatocelluar carcinoma risk in Korea. Br J Cancer. 2010;103(5):741-746.

17. Anyiwe K, Qiao Y, De P, Yoshida EM, Earle CC, Thein HH. Effect of socioeconomic status on hepatocellular carcinoma incidence and stage at diagnosis, a population-based cohort study. Liver Int. 2016;36(6):902-910. 
18. Pechey R, Monsivais P. Socioeconomic inequalities in the healthiness of food choices: exploring the contributions of food expenditures. Prev Med. 2016;88:203-209.

19. Benoit M, Leeman R, Maurer M Call to action: expand programs to feed our children. American Academy of Pediatrics. Available from: https://www.aappublications.org/news/2020/12/17/foodinse curity121720. Accessed September 3, 2021.

20. Darmon N, Drewnowski A. Contribution of food prices and diet cost to socioeconomic disparities in diet quality and health: a systematic review and analysis. Nutr Rev. 2015;73(10):643-660.

21. Fuhrman J. The Hidden Dangers of Fast and Processed Food. Am $J$ Lifestyle Med. 2018;12(5):375-381.

22. Kelli HM, Kim JH, Samman Tahhan A, et al. Living in Food Deserts and Adverse Cardiovascular Outcomes in Patients With Cardiovascular Disease. J Am Heart Assoc. 2019;8(4):e010694.

23. USDA. Characteristics and Influential Factors of Food Deserts. US Department of Health and Human Services. Available from: https://www.ers.usda.gov/webdocs/publications/45014/30940 err140.pdf. Accessed September 3, 2021.

24. Velazquez KT, Enos RT, Bader JE, et al. Prolonged high-fat-diet feeding promotes non-alcoholic fatty liver disease and alters gut microbiota in mice. World J Hepatol. 2019;11(8):619-637.

25. Yasutake K, Kohjima M, Kotoh K, Nakashima M, Nakamuta M, Enjoji M. Dietary habits and behaviors associated with nonalcoholic fatty liver disease. World J Gastroenterol. 2014;20 (7):1756-1767.

26. Piguet AC, Saran U, Simillion C, et al. Regular exercise decreases liver tumors development in hepatocyte-specific PTEN-deficient mice independently of steatosis. $J$ Hepatol. 2015;62(6):1296-1303.

27. Saran U, Guarino M, Rodriguez S, et al. Anti-tumoral effects of exercise on hepatocellular carcinoma growth. Hepatol Commun. 2018;2(5):607-620.

28. Yang JD, Mohamed HA, Cvinar JL, Gores GJ, Roberts LR, Kim WR. Diabetes Mellitus Heightens the Risk of Hepatocellular Carcinoma Except in Patients With Hepatitis C Cirrhosis. Am J Gastroenterol. 2016;111(11):1573-1580.

29. Suwannaphant K, Laohasiriwong W, Puttanapong N, Saengsuwan J, Phajan T. Association between Socioeconomic Status and Diabetes Mellitus: the National Socioeconomics Survey, 2010 and 2012. J Clin Diagn Res. 2017;11(7):LC18-LC22.

30. van Dijk JW, van Loon LJ. Exercise strategies to optimize glycemic control in type 2 diabetes: a continuing glucose monitoring perspective. Diabetes Spectr. 2015;28(1):24-31.

31. Graif C, Gladfelter AS, Matthews SA. Urban Poverty and Neighborhood Effects on Crime: incorporating Spatial and Network Perspectives. Sociol Compass. 2014;8(9):1140-1155.

32. Baruth M, Sharpe PA, Parra-Medina D, Wilcox S. Perceived barriers to exercise and healthy eating among women from disadvantaged neighborhoods: results from a focus groups assessment. Women Health. 2014;54(4):336-353.

33. Wen CP, Lin J, Yang YC, et al. Hepatocellular carcinoma risk prediction model for the general population: the predictive power of transaminases. J Natl Cancer Inst. 2012;104(20):1599-1611.

34. Zaydfudim V, Whiteside MA, Griffin MR, Feurer ID, Wright JK, Pinson CW. Health insurance status affects staging and influences treatment strategies in patients with hepatocellular carcinoma. Ann Surg Oncol. 2010;17(12):3104-3111.

35. Ryon EL, Kronenfeld JP, Lee RM, et al. Surgical management of hepatocellular carcinoma patients with portal vein thrombosis: the United States Safety Net and Academic Center Collaborative Analysis. J Surg Oncol. 2021;123(2):407-415.

36. Lee RM, Gamboa AC, Turgeon MK, et al. Dissecting disease, race, ethnicity, and socioeconomic factors for hepatocellular carcinoma: an analysis from the United States Safety Net Collaborative. Surg Oncol. 2020;35:120-125.
37. Lee RM, Gamboa AC, Turgeon MK, et al. The Evolving Landscape of Hepatocellular Carcinoma: a US Safety Net Collaborative Analysis of Etiology of Cirrhosis. Am Surg. 2020;86(7):865-872.

38. Vitiello GA, Wang A, Lee RM, et al. Surgical resection of early stage hepatocellular carcinoma improves patient survival at safety net hospitals. J Surg Oncol. 2021;123(4):963-969.

39. Turgeon MK, Lee RM, Gamboa AC, et al. Impact of hepatitis $\mathrm{C}$ treatment on long-term outcomes for patients with hepatocellular carcinoma: a United States Safety Net Collaborative Study. HPB (Oxford). 2021;23(3):422-433.

40. Kronenfeld JP, Ryon EL, Goldberg D, et al. Survival Inequity in Vulnerable Populations with Early-Stage Hepatocellular Carcinoma: A United States Safety-Net Collaborative Analysis. HPB (Oxford); 2020.

41. Wang J, Ha J, Lopez A, Bhuket T, Liu B, Wong RJ. Medicaid and Uninsured Hepatocellular Carcinoma Patients Have More Advanced Tumor Stage and Are Less Likely to Receive Treatment. J Clin Gastroenterol. 2018;52(5):437-443.

42. Mehta NJ, Celik AD, Peters MG. Screening for hepatocellular carcinoma: what is missing? Hepatol Commun. 2017;1(1):18-22.

43. Goldberg DS, Valderrama A, Kamalakar R, Sansgiry SS, Babajanyan S, Lewis JD. Hepatocellular Carcinoma Surveillance Among Cirrhotic Patients With Commercial Health Insurance. J Clin Gastroenterol. 2016;50(3):258-265.

44. Tou LC, Prakash N, Jeyakumar SJ, Ravi S. Investigating Social Determinants of Health in an Urban Direct Primary Care Clinic. Cureus. 2020;12(10):e10791.

45. Patel N, Yopp AC, Singal AG. Diagnostic delays are common among patients with hepatocellular carcinoma. J Natl Compr Canc Netw. 2015;13(5):543-549.

46. CDC. Guide To Clinical Preventive Services; An Assessment of the Effectiveness of 169 Interventions. US Department of Health and Human Services; 1998. Available from: https://wonder.cdc. gov/wonder/prevguid/p0000109/p0000109.asp. Accessed September 3, 2021.

47. Attwa MH, El-Etreby SA. Guide for diagnosis and treatment of hepatocellular carcinoma. World J Hepatol. 2015;7 (12):1632-1651.

48. Harris PS, Hansen RM, Gray ME, Massoud OI, McGuire BM, Shoreibah MG. Hepatocellular carcinoma surveillance: an evidence-based approach. World J Gastroenterol. 2019;25 (13):1550-1559.

49. Worland T, Harrison B, Delmenico L, Dowling D. Hepatocellular Carcinoma Screening Utilising Serum Alpha-Fetoprotein Measurement and Abdominal Ultrasound Is More Effective than Ultrasound Alone in Patients with Non-viral Cirrhosis. $J$ Gastrointest Cancer. 2018;49(4):476-480.

50. Marrero JA, Kulik LM, Sirlin CB, et al. Diagnosis, Staging, and Management of Hepatocellular Carcinoma: 2018 Practice Guidance by the American Association for the Study of Liver Diseases. Hepatology. 2018;68(2):723-750.

51. CDC. Hepatitis C Questions and Answers for the Public. Department of Health and Human Services; 2020. Available from: https://www.cdc.gov/hepatitis/hcv/cfaq.htm. Accessed September 3, 2021.

52. Zhang BH, Yang BH, Tang ZY. Randomized controlled trial of screening for hepatocellular carcinoma. J Cancer Res Clin Oncol. 2004;130(7):417-422.

53. Yang JD. Detect or not to detect very early stage hepatocellular carcinoma? The western perspective. Clin Mol Hepatol. 2019;25 (4):335-343.

54. Mukund A, Vats P, Jindal A, Patidar Y, Sarin SK. Early Hepatocellular Carcinoma Treated by Radiofrequency Ablation-Mid- and Long-Term Outcomes. J Clin Exp Hepatol. 2020;10(6):563-573. 
55. Graf D, Vallbohmer D, Knoefel WT, et al. Multimodal treatment of hepatocellular carcinoma. Eur J Intern Med. 2014;25 (5):430-437.

56. Singal AG, Tiro JA, Gupta S. Improving hepatocellular carcinoma screening: applying lessons from colorectal cancer screening. Clin Gastroenterol Hepatol. 2013;11(5):472-477.

57. Natale-Pereira A, Enard KR, Nevarez L, Jones LA. The role of patient navigators in eliminating health disparities. Cancer. 2011;117(15 Suppl):3543-3552.

58. Bernardo BM, Zhang $\mathrm{X}$, Beverly Hery CM, Meadows RJ, Paskett ED. The efficacy and cost-effectiveness of patient navigation programs across the cancer continuum: a systematic review. Cancer. 2019;125(16):2747-2761.

59. Ramachandran A, Freund KM, Bak SM, Heeren TC, Chen CA, Battaglia TA. Multiple barriers delay care among women with abnormal cancer screening despite patient navigation. $J$ Womens Health. 2015;24(1):30-36.

60. Dusetzina SB, Basch E, Keating NL. For uninsured cancer patients, outpatient charges can be costly, putting treatments out of reach. Health Aff. 2015;34(4):584-591.

61. Alese OB, Kim S, Chen Z, Ramalingam SS, Owonikoko TK, ElRayes BF. Analysis of liver-directed therapies in U.S. cancer patients. Curr Oncol. 2015;22(6):e457-461.

62. CMS. Global Surgery Booklet. US Department of Health and Human Services; 2020. Available from: https://www.cms.gov/out reach-and-education/medicare-learning-network-mln/mlnpro ducts/downloads/globallsurgery-icn907166.pdf. Accessed September 3, 2021.

63. Fiorillo $\mathrm{CE}$, Hughes $\mathrm{AL}$, Ic $\mathrm{C}$, et al. Factors associated with patient no-show rates in an academic otolaryngology practice. Laryngoscope. 2018;128(3):626-631.

64. Carvalho E, Bettger JP, Goode AP. Insurance Coverage, Costs, and Barriers to Care for Outpatient Musculoskeletal Therapy and Rehabilitation Services. $N$ C Med J. 2017;78(5):312-314.

65. Yao H, Bian X, Mao L, Zi X, Yan X, Qiu Y. Preoperative Enteral Nutritional Support in Patients Undergoing Hepatectomy for Hepatocellular Carcinoma: a Strengthening the Reporting of Observational Studies in Epidemiology Article. Medicine. 2015;94(46):e2006.

66. Gupta RP, de Wit ML, McKeown D. The impact of poverty on the current and future health status of children. Paediatr Child Health. 2007;12(8):667-672.

67. Nieuwenhuis J, Hooimeijer P. The association between neighbourhoods and educational achievement, a systematic review and meta-analysis. $J$ Hous Built Environ. 2016;31 (2):321-347.

68. Baugh AD, Vanderbilt AA, Baugh RF. The dynamics of poverty, educational attainment, and the children of the disadvantaged entering medical school. Adv Med Educ Pract. 2019;10:667-676.

69. Zajacova A, Lawrence EM. The Relationship Between Education and Health: reducing Disparities Through a Contextual Approach. Annu Rev Public Health. 2018;39:273-289.

70. Carrera PM, Kantarjian HM, Blinder VS. The financial burden and distress of patients with cancer: understanding and stepping-up action on the financial toxicity of cancer treatment CA Cancer J Clin. 2018;68(2):153-165.

71. Oldach BR, Katz ML. Health literacy and cancer screening: a systematic review. Patient Educ Couns. 2014;94(2):149-157.

72. Franco RA, Fan Y, Jarosek S, Bae S, Galbraith J. Racial and Geographic Disparities in Hepatocellular Carcinoma Outcomes. Am J Prev Med. 2018;55(5 Suppl 1):S40-S48.

73. Denniston MM, Jiles RB, Drobeniuc J, et al. Chronic hepatitis $\mathrm{C}$ virus infection in the United States, National Health and Nutrition Examination Survey 2003 to 2010. Ann Intern Med. 2014;160(5):293-300.
74. Harrison LE, Reichman T, Koneru B, et al. Racial discrepancies in the outcome of patients with hepatocellular carcinoma. Arch Surg. 2004;139(9):992-996.

75. Dakhoul L, Gawrieh S, Jones KR, et al. Racial Disparities in Liver Transplantation for Hepatocellular Carcinoma Are Not Explained by Differences in Comorbidities, Liver Disease Severity, or Tumor Burden. Hepatol Commun. 2019;3 (1):52-62.

76. Ananthakrishnan AN, Saeian K. Racial differences in liver transplantation outcomes in the MELD era. Am $J$ Gastroenterol. 2008;103(4):901-910.

77. Mathur AK, Sonnenday CJ, Merion RM. Race and ethnicity in access to and outcomes of liver transplantation: a critical literature review. Am J Transplant. 2009;9(12):2662-2668.

78. Genoff MC, Zaballa A, Gany F, et al. Navigating Language Barriers: a Systematic Review of Patient Navigators' Impact on Cancer Screening for Limited English Proficient Patients. J Gen Intern Med. 2016;31(4):426-434.

79. OMH. Profile: Hispanic/Latino Americans. US Department of Health and Human Services; 2019. Available from: https://minor ityhealth.hhs.gov/omh/browse.aspx?lvl=3\&lvlid=64. Accessed September 3, 2021.

80. Steinberg EM, Valenzuela-Araujo D, Zickafoose JS, Kieffer E, DeCamp LR. The "Battle" of Managing Language Barriers in Health Care. Clin Pediatr (Phila). 2016;55 (14):1318-1327.

81. Chavez LJ, Ornelas IJ, Lyles CR, Williams EC. Racial/ethnic workplace discrimination: association with tobacco and alcohol use. Am J Prev Med. 2015;48(1):42-49.

82. Beck TL, Le TK, Henry-Okafor Q, Shah MK. Medical Care for Undocumented Immigrants: national and International Issues. Physician Assist Clin. 2019;4(1):33-45.

83. Olazagasti C, Duma N. Cancer Care for All? Tales of Caring for Undocumented Patients with Cancer. Oncologist. 2020;25 (7):552-554.

84. Jacobson HE, Hund L, Soto Mas F. Predictors of English Health Literacy among U.S. Hispanic Immigrants: the importance of language, bilingualism and sociolinguistic environment. Lit Numer Stud. 2016;24(1):43-64.

85. Santos MG, Handley MA, Omark K, Schillinger D. ESL participation as a mechanism for advancing health literacy in immigrant communities. J Health Commun. 2014;19(Suppl 2):89-105.

86. Williams DR, Priest N, Anderson NB. Understanding associations among race, socioeconomic status, and health: patterns and prospects. Health Psychol. 2016;35(4):407-411.

87. Hill HD. Paid Sick Leave and Job Stability. Work Occup. 2013;40 (2):57.

88. Kim TJ. Is an insecure job better for health than having no job at all? A systematic review of studies investigating the health-related risks of both job insecurity and unemployment. BMC Public Health. 2015;15:985.

89. Sherman DW. A Review of the Complex Role of Family Caregivers as Health Team Members and Second-Order Patients. Healthcare. 2019;7(2):8574.

90. Murdock A, Rodgers C, Lindsay H, Tham TC. Why do patients not keep their appointments? Prospective study in a gastroenterology outpatient clinic. J R Soc Med. 2002;95 (6):284-286.

91. Kronenfeld JP, Penedo FJ. Novel Coronavirus (COVID-19): telemedicine and remote care delivery in a time of medical crisis, implementation, and challenges. Transl Behav Med. 2021;11 (2):659-663.

92. Myers US, Birks A, Grubaugh AL, Axon RN. Flattening the Curve by Getting Ahead of It: how the VA Healthcare System Is Leveraging Telehealth to Provide Continued Access to Care for Rural Veterans. J Rural Health. 2020;1:45. 
93. Witten NA, Humphry J. The Electronic Health Literacy and Utilization of Technology for Health in a Remote Hawaiian Community: lana'i. Hawaii J Med Public Health. 2018;77 (3):51-59.

94. Bittner M. First-Ever National Study: millions of People Rely on Library Computers for Employment, Health, and Education | bill \& Melinda Gates Foundation. Bill \& Melinda Gates Foundation; 2020. Available from: https://www.gatesfoundation.org/mediacenter/press-releases/2010/03/millions-of-people-rely-on-librarycomputers-for-employment-health-and-education. Accessed September 3, 2021.

95. Zach L, Dalrymple PW, Rogers ML, Williver-Farr H. Assessing internet access and use in a medically underserved population: implications for providing enhanced health information services. Health Info Libr J. 2012;29(1):61-71.

96. Kronenfeld JP, Goel N, Author Reflections: ASO. Access to Care and Screening Inequities for Patients At Risk for Hepatocellular Carcinoma. Ann Surg Oncol. 2021;28(4):1937-1938.

97. Glied S, Ma S, Borja AA. Effect of the Affordable Care Act on Health Care Access. Issue Brief. 2017;13:1-11.

98. Tilhou AS, Huguet N, DeVoe J, Angier H. The Affordable Care Act Medicaid Expansion Positively Impacted Community Health Centers and Their Patients. J Gen Intern Med. 2020;35(4):1292-1295.

99. Ko NY, Hong S, Winn RA, Calip GS. Association of Insurance Status and Racial Disparities With the Detection of Early-Stage Breast Cancer. JAMA Oncol. 2020.

100. Abudu B, Cook KA, Gershenwald JE, Cohen PR, Geller AC. Quantitative associations between health insurance and stage of melanoma at diagnosis among nonelderly adults in the United States. Cancer. 2020;126(4):775-781. doi:10.1002/cncr.32587

101. Sabik LM, Eom KY, Dahman B, et al. The Impact of Massachusetts Health Reform on Colorectal and Breast Cancer Stage at Diagnosis. Med Care. 2020;58(2):183-191. doi:10.1097/ MLR.0000000000001241

102. Hahn RA, Truman BI. Education Improves Public Health and Promotes Health Equity. Int J Health Serv. 2015;45(4):657-678. doi:10.1177/0020731415585986

103. Duncan GJ, Magnuson K, Murnane RJ. Reforming Preschools and Schools. Academic Pediatrics. 2016;16(3):S121-127. doi:10.1016/j.acap.2015.12.003

104. Vaughn MG, Witko C. Does the amount of school choice matter for student engagement? Soc Sci J. 2013;50(1):23-33. doi:10.1016/j.soscij.2012.07.004

105. EFS. Why School Choice Now. US Department of Education. Available from: https://sites.ed.gov/freedom/2020/09/22/whyschool-choice-now/. Accessed September 3, 2021.

106. Adams RJ. Improving health outcomes with better patient understanding and education. Risk Management and Healthcare Policy. 2010;3:61-72. doi:10.2147/RMHP.S7500

107. Daniel SJ. Education and the COVID-19 pandemic. Prospects. 2020;2:1-6.

108. CDC. Operational Strategy for K-12 Schools through Phased Prevention. US Department of Health and Human Services; 2020. Available from: https://www.cdc.gov/coronavirus/2019ncov/community/schools-childcare/operation-strategy.html. Accessed September 3, 2021.

109. Van Lancker W, Parolin Z. COVID-19, school closures, and child poverty: a social crisis in the making. Lancet Public Health. 2020;5(5):e243-e244. doi:10.1016/S2468-2667(20)30084-0

110. Betz CL. COVID-19 and school return: the need and necessity. Journal of Pediatric Nursing. 2020;54:A7-A9. doi:10.1016/j. pedn.2020.07.015

111. Konjeti VR, Heuman D, Bajaj JS, et al. Telehealth-Based Evaluation Identifies Patients Who Are Not Candidates for Liver Transplantation. Clin Gastroenterol Hepatol. 2019;17 (1):207-209 e201. doi:10.1016/j.cgh.2018.04.048
112. Penedo FJ, Oswald LB, Kronenfeld JP, Garcia SF, Cella D, Yanez B. The increasing value of eHealth in the delivery of patient-centred cancer care. Lancet Oncol. 2020;21(5):e240e251. doi:10.1016/S1470-2045(20)30021-8

113. Almathami HKY, Win KT, Vlahu-Gjorgievska E. Barriers and Facilitators That Influence Telemedicine-Based, Real-Time, Online Consultation at Patients' Homes: systematic Literature Review. J Med Internet Res. 2020;22(2):e16407. doi:10.2196/ 16407

114. Reddick CG, Enriquez R, Harris RJ, Sharma B. Determinants of broadband access and affordability: an analysis of a community survey on the digital divide. Cities. 2020;106:102904. doi:10.1016/j.cities.2020.102904

115. Choi NG, Dinitto DM. The digital divide among low-income homebound older adults: internet use patterns, eHealth literacy, and attitudes toward computer/Internet use. $J$ Med Internet Res. 2013;15(5):e93. doi:10.2196/jmir.2645

116. Locatelli SM, Sharp LK, Syed ST, Bhansari S, Gerber BS. Measuring Health-related Transportation Barriers in Urban Settings. J Appl Meas. 2017;18(2):178-193.

117. Syed ST, Gerber BS, Sharp LK. Traveling towards disease: transportation barriers to health care access. J Community Health. 2013;38(5):976-993. doi:10.1007/s10900-013-9681-1

118. Wolfe MK, McDonald NC. Innovative health care mobility services in the US. BMC Public Health. 2020;20(1):906. doi:10.1186/s12889-020-08803-5

119. Chaiyachati KH, Moore K, Adelberg M. Too Early to Cut Transportation Benefits From Medicaid Enrollees. Health Serv Insights. 2018;12:1178632918804817.

120. Schooley BL, Horan TA, Lee PW, West PA. Rural veteran access to healthcare services: investigating the role of information and communication technologies in overcoming spatial barriers. Perspect Health Inf Manag. 2010;7:1f.

121. Kronenfeld JP, Graves KD, Penedo FJ, Yanez B. Overcoming Disparities in Cancer: a Need for Meaningful Reform for Hispanic and Latino Cancer Survivors. The Oncologist. 2021;26 (6):443-452. doi:10.1002/onco.13729

122. Harrison R, Walton M, Chauhan A, et al. What is the role of cultural competence in ethnic minority consumer engagement? An analysis in community healthcare. Int $J$ Equity Health. 2019;18(1):191. doi:10.1186/s12939-019-1104-1

123. Hawley ST, Morris AM. Cultural challenges to engaging patients in shared decision making. Patient Educ Couns. 2017;100 (1):18-24. doi:10.1016/j.pec.2016.07.008

124. Cyril S, Smith BJ, Possamai-Inesedy A, Renzaho AM. Exploring the role of community engagement in improving the health of disadvantaged populations: a systematic review. Glob Health Action. 2015;8:29842.

125. Jongen C, McCalman J, Bainbridge R. Health workforce cultural competency interventions: a systematic scoping review. $B M C$ Health Serv Res. 2018;18(1):232.

126. American Society of Clinical O. The State of Cancer Care in America, 2017: a Report by the American Society of Clinical Oncology. J Oncol Pract. 2017;13(4):e353-e394.

127. Occa A, Morgan SE, Potter JE. Underrepresentation of Hispanics and Other Minorities in Clinical Trials: recruiters' Perspectives. J Racial Ethn Health Disparities. 2018;5 (2):322-332.

128. AAMC. Table 13. Practice Specialty, Males by Race/ Ethnicity, 2018; 2018. Available from: https://www.aamc.org/data-reports /workforce/data/table-13-practice-specialty-males-race/ethnicity2018. Accessed September 3, 2021.

129. Perez GK, Mutchler J, Yang MS, Fox Tree-Mcgrath C, Park ER. Promoting quality care in patients with cancer with limited English proficiency: perspectives of medical interpreters. Psychooncology. 2016;25(10):1241-1245. 
130. Karliner LS, Jacobs EA, Chen AH, Mutha S. Do professional interpreters improve clinical care for patients with limited English proficiency? A systematic review of the literature. Health Serv Res. 2007;42(2):727-754.

131. Panayiotou A, Gardner A, Williams S, et al. Language Translation Apps in Health Care Settings: expert Opinion. JMIR Mhealth Uhealth. 2019;7(4):e11316.

132. Hebert JR, Braun KL, Meade CD, Bloom J, Kobetz E. Community-Based Participatory Research Adds Value to the National Cancer Institute's Research Portfolio. Prog Community Health Partnersh. 2015;9 Suppl:1-4.

133. Graves KD, Jensen RE, Canar J, et al. Through the lens of culture: quality of life among Latina breast cancer survivors. Breast Cancer Res Treat. 2012;136(2):603-613.
134. Rivera-Hernandez M. The role of religious leaders in health promotion for older Mexicans with diabetes. $J$ Relig Health. 2015;54(1):303-315.

135. Sharma AE, Huang B, Knox M, Willard-Grace R, Potter MB. Patient Engagement in Community Health Center Leadership: how Does it Happen? J Community Health. 2018;43 (6):1069-1074.

136. Carrasquillo O, Seay J, Jhaveri V, et al. Increasing uptake of evidence-based screening services though a community health worker-delivered multimodality program: study protocol for a randomized pragmatic trial. Trials. 2020;21(1):368.

137. Birkhauer J, Gaab J, Kossowsky J, et al. Trust in the health care professional and health outcome: a meta-analysis. PLoS One. 2017;12(2):e0170988.

\section{Publish your work in this journal}

The Journal of Hepatocellular Carcinoma is an international, peerreviewed, open access journal that offers a platform for the dissemination and study of clinical, translational and basic research findings in this rapidly developing field. Development in areas including, but not limited to, epidemiology, vaccination, hepatitis therapy, pathology and molecular tumor classification and prognostication are all considered for publication. The manuscript management system is completely online and includes a very quick and fair peer-review system, which is all easy to use. Visit http://www.dovepress.com/ testimonials.php to read real quotes from published authors.

Submit your manuscript here: https://www.dovepress.com/journal-of-hepatocellular-carcinoma-journal 